\title{
Entre motivaciones y efectos. Movilidades residenciales en la Argentina contemporánea
}

\author{
In-between motivations and effects. \\ Residential mobility in contemporary Argentina
}

Lucía de Abrantes [l] Luciana Trimano [II]

\begin{abstract}
Resumen
La investigación explora las tensiones que los "movimientos residenciales" provenientes de la gran ciudad generan sobre localidades pequeñas y medianas de la Argentina contemporánea. A la luz de dos casos etnográficos, presenta un modelo bidimensional para recuperar las motivaciones de los flujos metropolitanos y atender a los efectos que estos desplazamientos producen sobre territorios concretos, modalidades de sociabilidad, percepciones temporales y procesos de identidad. Desde aquí problematizamos, además, algunos de los conceptos más arraigados en las trayectorias de las ciencias sociales.
\end{abstract}

Palabras clave: movilidades residenciales; motivaciones; transformaciones; intersticios.

\begin{abstract}
This research study explores the tensions that "residential movements" coming from big cities generate on small and medium-sized cities in contemporary Argentina. In the light of two ethnographic cases, the study presents a bi-dimensional model to retrieve the motivations of metropolitan flows and to take into account the effects that mobility produces on specific territories, sociability patterns, temporal perceptions and identity processes. Moreover, through this study we challenge some of the concepts most deeply rooted in the history of the social sciences.
\end{abstract}

Keywords: residential mobility; motivations; transformations, interstices. 


\section{Introducción}

Desde los años setenta, los núcleos centrales de las áreas metropolitanas dejaron de atraer, por primera vez en la historia, efectivos poblacionales y comenzaron un lento declive en el número de sus habitantes, mientras, sus periferias residenciales crecieron a un ritmo constante y creciente. A su vez, otras áreas urbanas no metropolitanas, núcleos urbanos de menor tamaño, y aún áreas rurales distantes, iniciaron un sustancial crecimiento demográfico basado, esencialmente, en los desplazamientos definitivos de población (Arroyo, 2001; Meichtry, 2007). A pesar de su peso relativo, las "movilidades residenciales" que se despliegan desde las grandes ciudades hacia pequeñas y medianas aglomeraciones, en la Argentina, es un campo de estudio escasamente problematizado en el ámbito de las ciencias sociales locales (Trimano y de Abrantes, 2017 y 2018; de Abrantes y Trimano, 2019).

Los motivos vinculados a esta vacancia en las agendas de investigación - y por ende a la invisibilización del fenómeno - son diversos. Por un lado, observamos que los estudios urbanos y rurales han tendido a focalizar los abordajes en los límites de sus territorios paradigmáticos (el campo y la metrópolis), olvidando los movimientos que se producen entre ambas espacialidades. Por otro lado, los estudios abocados a los desplazamientos poblacionales han dirigido sus reflexiones, casi de forma exclusiva, a reponer las problemáticas que despuntan las corrientes internacionales, desatendiendo el volumen de los cambios internos (Perren, 2011, p. 7), descuidando los impactos generados en los sitios de acogida y poniendo el acento en la unicausalidad del moverse del sujeto migrante (Arango, 1998). Estas razones, sumado a la ausencia de estudios comparativos (Masseroni, 2018), han socavado la posibilidad de conocer cabalmente el fenómeno.

Encontramos, a su vez, que si bien los investigadores inscriptos en el "giro de la movilidad" (Urry, 2007), señalaron la relevancia de este tipo de desplazamiento al momento de analizar la compleja trama de los territorios, no terminan de abrazar el problema (Zunino, Giucci y Jirón, 2017). Indicio de ello es la escasa producción de trabajos, impulsados desde este paradigma, que tengan por objeto el movimiento poblacional que nos ocupa.

En este escenario, la presente investigación analiza las tensiones que los desplazamientos humanos residenciales internos generan en localidades pequeñas y medianas de la Argentina contemporánea. El objetivo es presentar un registro de lectura teórico-metodológico, un modelo analítico, que permita el análisis de la movilidad y los territorios. El modelo que decidimos denominar como "para armar" - porque invita a la construcción continua de categorías - se estructura en base a dos dimensiones clave: las motivaciones de los flujos poblacionales metropolitanos y los efectos que éstos generan en las sociedades receptoras y los territorios de acogida.

La díada conceptual elaborada, a diferencia de otras perspectivas, emerge de la lectura de referentes empíricos: dos localidades argentinas, una rural y otra urbana, que se han visto fuertemente atravesadas por las movilidades residenciales, que involucran, también, un cambio de escala. De esta manera, la inteligibilidad del objeto se apoya en dos interrogantes: ¿Desde qué prisma es posible 
comprender una realidad emergente y móvil? ¿Qué elementos experienciales y situados definen los motivos y los efectos?

\section{La potencia de la movilidad}

El presente trabajo hace foco en un tipo de desplazamiento que fue acogido -aunque muy marginalmente- por las ciencias sociales y los estudios migratorios, que tendieron a clasificarlo como "interno" (Lattes, 2007) e "inverso" (Nakayama y Marioni, 2007). Las razones de esta clasificación se sustentan en cuatro premisas: se desarrolla dentro del territorio nacional, se diferencia de aquellos desplazamientos transfronterizos, sus móviles versan sobre la búsqueda de mejores oportunidades de vida - culturales o ambientales -, y, finalmente, se dirige a contrapelo de la corriente clásica (de las grandes ciudades hacia aglomeraciones, tanto urbanas como rurales, de menor tamaño).

Los movimientos internos adquirieron un rol protagónico en la Argentina de los años cincuenta cuando el conocido éxodo rural, que engrosó las bases de los sectores populares metropolitanos, se postuló como un fenómeno capaz de iluminar la emergencia y consolidación del peronismo (Germani, 1974). Sin embargo, con el tiempo, perdieron terreno frente al avance de las explicaciones volcadas hacia los desplazamientos internacionales (Perren, 2011). Hace dos décadas, el fenómeno volvió a posicionarse y exiguos estudios locales comenzaron a explorarlo importando un repertorio de términos ya consolidados en otras latitudes y haciendo hincapié en el carácter inverso de los nuevos movimientos: "neorruralidad" (Chevalier,
1981), "naturbanización" (Prados, 2011), "rururbanización" (Nates Cruz y Velásquez López, 2019), "migración por estilo de vida" (Benson y O’Reilly, 2009), "migración residencial" (Gurran, 2011) o "de amenidad" (Moss, 2006), entre otros.

Las investigaciones realizadas en dos localidades argentinas, con eje en la movilidad residencial, nos permitieron comprender que la experiencia de los desplazamientos internos desborda a la propuesta migratoria. Reconociendo los aportes realizados desde este corpus de trabajos, en este artículo nos deslizamos desde el paradigma tradicional, que ha tendido a trabajar estos movimientos, para posicionarnos en el paradigma de la movilidad (Urry, 2007) que, paradójicamente, si bien presenta una gran potencialidad para tratar el fenómeno, no ha dirigido sus esfuerzos hacia este tipo de objeto. Este corrimiento no busca instalar un nuevo problema sino, y quizás más importante, proponer otro modo de abordarlo (Cosacov y Di Virgilio, 2019).

En términos generales, la perspectiva móvil postula la necesidad de correr el foco de atención y reemplazar las metáforas hegemónicas, como las de "orden social", "estructura", "sociedad", por las de "redes", "flujos" y "fluidos". Nos invita, en este sentido, a mirar "el movimiento (real o imaginado, potencial o deseado) de personas, objetos orgánicos e inorgánicos, dinero, información, recursos, etc., así como los momentos de fricción, éxtasis e inmovilidad" (Zunino, Giucci y Jirón, 2018); todo ello frente a las formas "a-móviles" (sin movimiento) del sistema anterior. En palabras de Tim Creswel (2006), un sistema - moderno - que necesitó fijar a la movilidad porque no encontró un modo de pensarla con las herramientas analíticas disponibles. 
Los promotores del giro de la movilidad hicieron hincapié en la necesidad de crear modelos específicos de investigación capaces de capturar y representar tipos de movimiento, así como las prácticas vinculadas a ellos. Los métodos móviles, como explican Sheller y Urry, "no sólo mezclan aproximaciones cualitativas, cuantitativas, visuales y experimentales (...), sino que también intervienen en problemas "aplicados" definiendo lo empírico en formas innovadoras que apuntan hacia nuevos problemas" (2018, p. 335).

\section{Modelo "para armar". Entre motivaciones y efectos}

El estudio de la movilidad residencial en escenarios no metropolitanos ha impulsado la revisión de los instrumentos metodológicos clásicos y el consecuente desarrollo de técnicas capaces de capturar las huellas de los movimientos (Jirón, 2012). De esta forma avanzamos en la creación de una perspectiva compleja, de un registro móvil, que pueda ajustarse a las peculiaridades de un conjunto de trayectorias en movimiento que articulan el abandono de un escenario, el tránsito hacia otro y, también, el afincamiento en un nuevo lugar de residencia.

Nuestro propósito es registrar la movilidad a partir de un conjunto de elementos experienciales (prácticas y representaciones) que organizamos en un modelo analítico. El modelo, que implica dos dimensiones centrales, un conjunto de segmentos experienciales y que ejecuta diversas técnicas de recolección cualitativas, es sólo una manera de aproximarse al problema, existiendo otras combinaciones posibles, así como piezas a incluir. Se trata de una propuesta (abierta, múltiple y sujeta a los requerimientos situados) sostenida en métodos móviles que ha funcionado para tratar la complejidad de nuestros casos de estudio, pero que puede hacerse extensiva a otras realidades.

El esquema con el que buscamos iluminar la movilidad invita, por un lado, a recuperar el universo motivacional de las personas que se trasladan desde las grandes urbes hacia las pequeñas y medianas localidades; y por otro, a reflexionar sobre los efectos que produce el arribo de actores con trayectorias metropolitanas sobre territorios concretos, temporalidades disímiles, modalidades de sociabilidad local e identidades ancladas. La división analítica planteada no surge de la abstracción teórica, sino de la experiencia de los actores, quienes, a través de sus representaciones y prácticas, dibujan la traza del movimiento.

Al no existir datos estadísticos ${ }^{1}$ que permitan determinar las razones de aquellos actores que se movilizan, así como los efectos que estos movimientos producen, discutimos a partir de referentes empíricos. La metodología, de este modo, se sustenta en un trabajo de campo prolongado y sostenido en el seno de una ciudad no metropolitana y de un pueblo rural, e involucra la aplicación de múltiples técnicas de recolección de datos de corte cualitativo. Con el desafío de seguir y reconstruir las huellas del movimiento, hemos realizado entrevistas en profundidad, observaciones, recorridos comentados, mapeos colectivos, historias de vida, análisis de fuentes documentales, entre otras. Si bien desarrollamos un ejercicio etnográfico 
localizado, que confronta y conjuga las experiencias de dos casos paradigmáticos, la investigación entabla relaciones entre las transformaciones situadas y problemáticas sociales más amplias.

El modelo se construyó sobre la base de dos investigaciones de corte etnográfico desarrolladas en una localidad rural de la provincia de Córdoba y una localidad urbana de la provincia de Buenos Aires (Figura 1). En estas aglomeraciones, escenarios arquetípicos del corredor turístico argentino, las movilidades residenciales han generado profundos cambios en los modos de habitar, experimentar e interpretar estos espacios.
El pueblo rural y la ciudad turística

El pueblo rural de Las Calles, situado en el valle de Traslasierra, comenzó a formarse en 1845 , siendo conocido como Las Cuatro Esquinas. Sus orígenes se remontan a los tiempos de la colonia ya que el camino Real al Alto Perú ${ }^{3}$ pasaba por este caserío cuya particularidad era el cruce de calles; de allí el origen de su nombre actual. En aquel tiempo era una pedanía del municipio de $\mathrm{Nono}^{4} \mathrm{y}$ recién se constituye como comuna ${ }^{5}$ en el año 1992. Según versiones lugareñas, el poblado, que entre los años cuarenta y cincuenta del siglo XX vivió básicamente del cultivo de tabaco y de la cría y faena de animales, nace

Figura 1 - Casos etnográficos

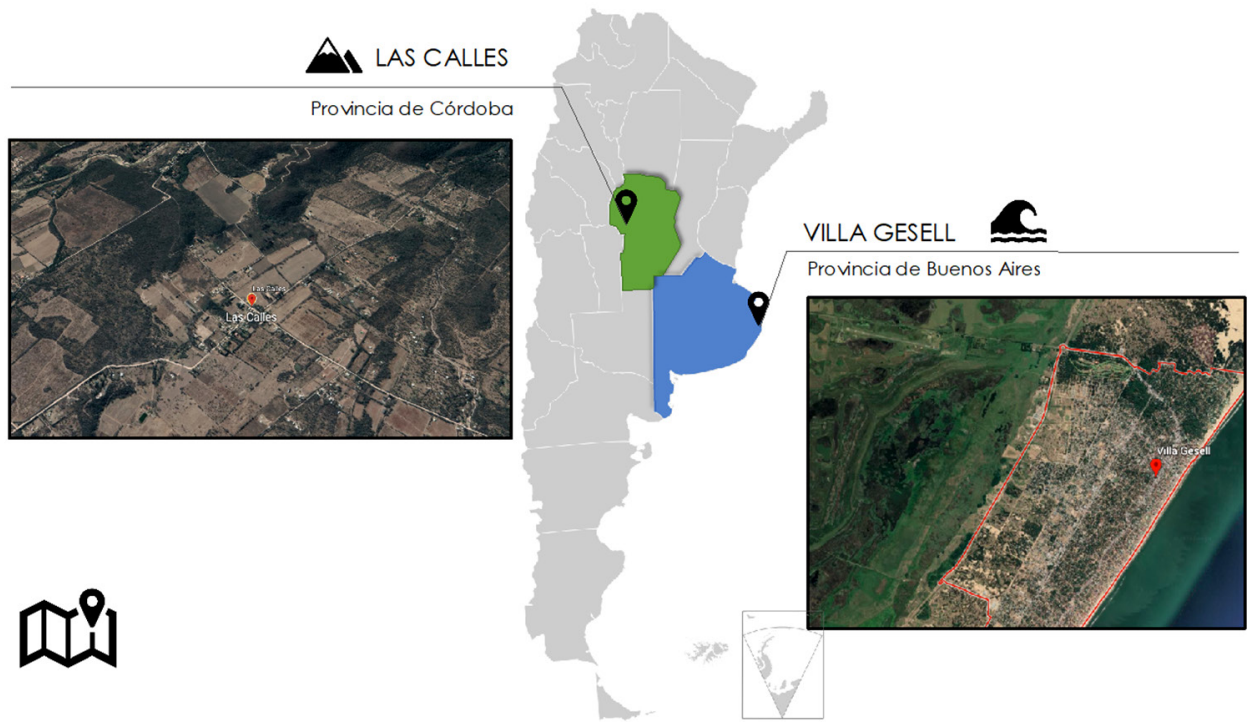

Fuente: elaboración propia en base a datos de Google Maps. 
de una colonia inglesa y desde su inicio ha ido acrecentando su población a partir del arribo de diversos flujos poblacionales (Trimano, 2017, 2019).

Al apelar a la periodización nativa, ${ }^{6}$ las dinámicas de los desplazamientos humanos hacia Las Calles se organizan en tres momentos paradigmáticos. Un primer período (19471960) caracterizado por el afincamiento de inmigrantes jubilados de origen británico, con gran acumulación de capital económico, social y cultural, que arribaron atraídos por un turismo terapéutico: "los gringos auténticos". Esta comunidad se estableció en un paraje virgen aledaño al casco céntrico del pueblo, llamado El Huaico ${ }^{7}$ y desde allí emprendieron la ordenación de una zona residencial, reproduciendo el estilo campestre británico, que los "callejeros" (o nacidos y criados) nombraron como "el barrio de los ingleses", "de la gente de plata", "de la gente elegante" o "los de arriba".

Entre 1960 y los 2000 surge un segundo movimiento poblacional, ahora nacional, proveniente en su mayoría desde Buenos Aires. Por sus características fenotípicas, económicas y simbólicas, los nativos asociaron a los citadinos con los británicos de antaño y los denominaron "gringos". Los nuevos habitantes arribaron a la comarca por líneas de parentesco y efectos de sucesión hereditaria afincandose también en El Huaico.

En el período reciente, que se extiende desde el 2000 hasta la actualidad, toma fuerza una tercera ola interprovincial ${ }^{8}$ (proveniente del $A M B A^{9}$ y del $A M C ;{ }^{10}$ ver Figura 2) cuyas motivaciones varían desde la apuesta políticoterritorial al orden espiritual y religioso: "los hippies". Estos actores coinciden con la presencia de inversores inmobiliarios - los "cabañeros" - que buscan desarrollar y satisfacer la demanda turística.

Por su parte, la localidad de Villa Gesell, ciudad mediana situada en el Corredor Atlántico de la provincia de Buenos Aires, fue fundada en 1931. Las hectáreas sobre las cuales hoy se levanta la ciudad balnearia fueron consideradas durante mucho tiempo como tierras improductivas: constituían los fondos de las pujantes estancias ganaderas y agrícolas de la provincia de Buenos Aires. Sin embargo, la cercanía al mar, las virtudes paisajísticas del lugar y el auge del turismo costero en el territorio nacional, fueron incentivando la creación de una villa balnearia. Bajo esta iniciativa, las hectáreas antes desestimadas se valorizaron y se convirtieron en una buena inversión para ciertas familias pudientes radicadas en el AMBA.

Del mismo modo que Las Calles, Villa Gesell fue nutriéndose de diversos desplazamientos poblaciones con características bien diversas (de Abrantes, 2018). Los nativos coinciden en señalar tres momentos paradigmáticos. El primero de ellos se extiende entre su fundación y 1960 cuando un conjunto de familias de procedencia europea decidieron instalarse en este pueblo - de no más de mil habitantes para formar parte de la épica de la fundación. Estas familias, constituidas por "los pioneros", no sólo aportaron el capital económico, necesario para la expansión de la ciudad, sino que también engrosaron las filas de los residentes permanentes. Se instalaron en el conocido Barrio Norte, una zona rodeada de pinos y caracterizada por una trama urbana zigzagueante cuyas calles continúan la morfología natural de los médanos. Además, fueron quienes otorgaron una primera 
impronta estética a la villa balnearia con la multiplicación de chalets de líneas uniformes a dos aguas y de techos rojos - emplazados en lotes extensos.

En esta época también arribaron a Villa Gesell familias argentinas, "los paisanos", de zonas rurales aledañas que se ubicaron en territorios más alejados de la costa y que constituyeron la mano de obra de los emprendimientos que surgían en la zona. Más aún, estos sectores suelen ser invisibilizados de las narrativas oficiales que tienden a señalar el carácter multiétnico y europeo del contexto fundacional.

Los geselinos identifican un segundo momento que comienza a delinearse en 1960, cuando Villa Gesell se consolida como uno de los destinos turísticos más demandados del país, y culmina en 1980. En esta etapa se registra un gran crecimiento poblacional nutrido de familias procedentes del AMBA. El relato aluvional insiste en remarcar las características de los grupos de nuevos pobladores que adquirieron mayor visibilidad en la villa balnearia de esta época. Por un lado, encontramos a las familias de clase media que se movilizaron hasta aquí atraídas por la potencialidad de diversos emprendimientos turísticos. Por otro, a "los hippies" que hicieron de Villa Gesell la cuna nacional de su movimiento cultural (Noel y de Abrantes, 2014).

El tercer momento se inicia en los años ochenta y se extiende hasta la actualidad. Este flujo poblacional es el más populoso de todos: en estas décadas se evidencian los saltos intercensales más significativos (según fuentes del INDEC entre el $30 \%$ y $50 \%$ ). A su vez, durante esta etapa se desarrollan con más fuerza las localidades del sur de Villa Gesell diferenciándose de los barrios más tradicionales de la ciudad. Los geselinos también identifican dos grandes grupos para este último movimiento de procedencia urbana y metropolitana: los "nuevos hippies", familias de clase media que se movilizan bajo un proyecto de vida alternativo y se instalan en las localidades del sur; y "los del conurbano", una gran masa de desempleados atraídos por el empleo estacional que el turismo motoriza (ver Figura 2). Este último sector, comienza a situarse en las periferias - en el trasfondo de la ciudad turística - dándole forma a los barrios y asentamientos populares de la localidad (Noel y de Abrantes, 2014).

El pueblo rural y la ciudad turística son escenarios que, desde sus orígenes, han estado acostumbrados al movimiento, recibiendo masas poblacionales de diversa procedencia. ${ }^{12}$ Si bien las distintas etapas de las periodizaciones nativas encierran un gran valor heurístico, a los fines de nuestra investigación nos centramos en analizar comparativamente el movimiento metropolitano que se intensifica en los años noventa. El recorte sobre este último período se fundamenta en que la magnitud del crecimiento poblacional, producto de estos últimos desplazamientos, ha desencadenado diversas pujas de sentido e impulsado la pregunta por la identidad del espacio y de quienes habitan allí: ¿Qué fuimos? ¿Qué somos? ¿En qué devenimos? ¿Hasta dónde podemos crecer y transformarnos? Estos fueron los interrogantes disparadores utilizados para construir el modelo bidimensional con el que abordamos la compleja trama motorizada por las movilidades.

Al hablar de las motivaciones, indagamos en las iniciativas y circunstancias de aquellas personas que deciden abandonar los escenarios metropolitanos para trasladarse 
Figura 2 - Movilidades entre áreas metropolitanas y escenarios no-metropolitanos de la Argentina

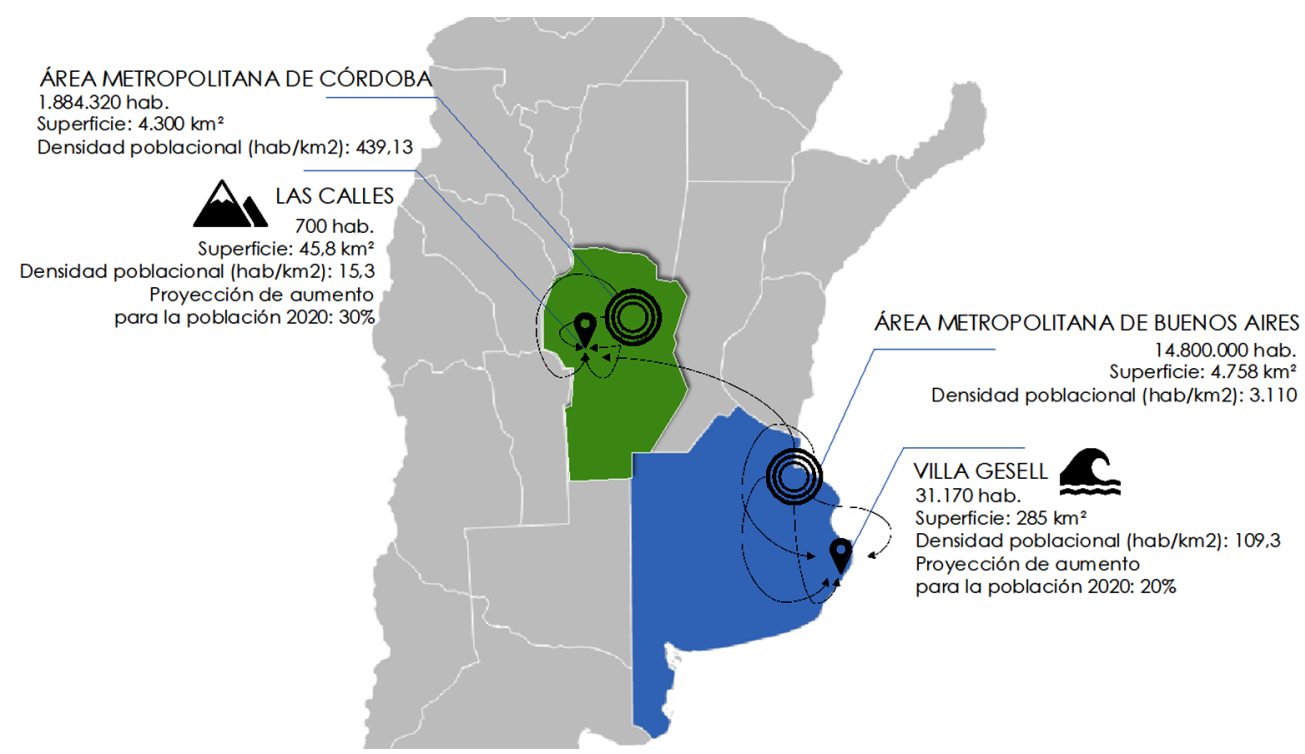

Fuente: elaboración propia en base a datos brindados por el Censo 2010 - Indec.

a pequeñas y medianas localidades: ¿Qué los moviliza? ¿Qué recursos (económicos, sociales, culturales, paisajísticos) los atraen? ¿Cuáles son sus representaciones de la gran ciudad, el campo, el pueblo o la villa balnearia? ¿Qué encuentran cuando llegan? ¿Qué experimentan cuando arriban al nuevo territorio? ¿Qué extrañan de aquello que dejaron? ¿Qué conflictos se desencadenan? En otras palabras, siguiendo la narrativa de la indagación, atendemos a una suite rítmica de rechazo y atracción en el proceso de motivación y en la toma de decisión de las personas que tienen que generar un nuevo proyecto de vida: que incluye cambiar de morada, radicarse e involucrarse con quienes ya habitan el territorio al que se arriba.
Asimismo, exploramos los efectos producidos por el flujo de las grandes ciudades a pequeñas localidades a partir de tres transformaciones detectadas in situ: las espaciales, las temporales y las relacionales. El principal supuesto que guía la indagación es que la diversidad de trayectorias, procedencias, pertenencias y tradiciones impactan en la configuración social de estos escenarios. En concordancia con esta intuición, objetivamos las fricciones, simbólicas y materiales, que emergen en las micro-sociedades reactualizadas en el encuentro de los imaginarios, deseos, expectativas y prácticas de habitantes que gestionan su existencia de manera diversa; y que, precisamente, debido a esa coincidencia espacio-temporal, 
se posicionan en un juego de "rivalidad por la autoridad simbólica" (Thompson, 1995) del territorio habitado y compartido.

En las líneas que siguen, entonces, reconstruimos un abanico de repertorios nativos sobre las implicancias del movimiento residencial. Esta construcción nos permite reponer las representaciones y prácticas de los citadinos que se mueven y también habilita la recuperación de una narrativa local y de modos de habitar donde queda plasmado cómo se conciben los impactos del flujo residencial. ¿Qué nuevos órdenes espaciales, temporales y sociales trae aparejado el fenómeno de movilidad? ¿Cómo interpretan y practican los actores las transformaciones que experimentan?

\section{Los motivos anudados al movimiento}

El objetivo de la investigación no es indagar directamente en las razones ni determinar una única causa capaz de impulsar a una persona o a un grupo a moverse, sino enmarcar la movilidad en el conjunto de prácticas y representaciones en torno "al lugar abandonado" y "al lugar deseado". Así, entre los imaginarios que se despliegan sobre "lo que se deja" y aquellos sobre "lo que se va a buscar", entre "las elegías y el encanto" (Trimano y de Abrantes, 2018), elaboramos una "constelación de motivos" que versan sobre diversos tópicos que emergieron como hallazgos etnográficos en nuestros trabajos de campo y que luego fueron sistematizados mediante el ejercicio comparativo.
La naturaleza, como foco de tracción, aparece en la mayoría de los relatos nativos como uno de los elementos decisivos del desplazamiento. Lejos de las tradicionales razones económicas, quienes deciden trasladarse señalan que los escenarios de menor escala les permiten experimentar la extensión de lo natural, así como un contacto más estrecho, íntimo y cotidiano con un paisaje menos intervenido. En contraposición, argumentan que el habitar las grandes urbes "los desconecta" de esta experiencia, cuasi ancestral, ya que en estos espacios la naturaleza aparece reducida frente al despliegue o la preponderancia de lo construido. Al respecto, también indican que en las grandes ciudades "el cemento", "los cableados", "el asfalto", "los edificios", etc., avanzan sobre el paisaje verde incentivando prácticas poco saludables: "Venimos buscando estar cerca de la naturaleza, (...) salimos de las ciudades para vivir tranquilos" (MLC 55 años). ${ }^{13}$

Por otro lado, la relación estrecha con la naturaleza habilitaría, para ellos, un registro del habitar más vigoroso y placentero que ignora algunas de las convenciones sociales y atiende a los movimientos de lo nohumano. Una habitante da cuenta de dicha transformación con estas palabras: "El estar más cerca de las estaciones, más consciente del efecto de la luna, si es primavera u otoño, sentir como se manifiesta el manto verde en el entorno y los pájaros" (MLC, 57 años).

A su vez, la cercanía con la materia viva, tan preciada para quienes se mueven, impulsa una red de prácticas afines que pretenden enmarcarse en un entorno biosocial: ${ }^{14}$ la alimentación saludable, el desarrollo de la agroecología y el cuidado del ambiente son 
algunos de los elementos destacados. En las observaciones constatamos, por ejemplo, que las tareas de jardinería y huerta son prácticas recurrentes entre los habitantes. La multiplicación de tiendas de venta de productos orgánicos y caseros también es otro dato significativo de estas localidades que promueven una alimentación sana y la producción directa de alimentos.

Asimismo, las sierras y el mar, los dos elementos que marcan el paisaje de los casos bajo estudio, aparecen como generadores de significados terapéuticos y como un modo de adaptación a las condiciones de existencia. El cuidado de sí mismo, orientado al logro de la felicidad, tiene su base tanto en las virtudes de la "autopercepción" como de "autocorrección" de ciertos males que genera la gran ciudad. Desde esta visión, la gran ciudad enferma el cuerpo y deshumaniza las relaciones personales: "Cuando Ilegué al valle hice mucho trabajo interior. Me quería ir de Buenos Aires, estaba muy cansada de la ciudad (...). Quería ir a un lugar donde merca [cocaína] no, drogas no" (MLC, 33 años). "La ciudad me estaba matando (...), me consumía, me llevaba a los extremos, me destruía (...) y decidí huir" (MVG, 40 años).

Desde otro ángulo, identificamos, en ambas localidades, el trabajo de asociaciones vecinales que se encuadran bajo cierto movimiento ambientalista y proteccionista: la naturaleza, así, se coloca como objeto a proteger, cuidar y preservar de las intervenciones humanas. Este acontecer queda reflejado, por ejemplo, en un conjunto de iniciativas locales en las que hemos participado: asambleas para frenar el desarrollo de proyectos inmobiliarios que atentan contra la virginidad del paisaje o el patrimonio arqueológico; reuniones comunitarias y debates públicos en donde se discute en qué medida la construcción de caminos de acceso o el desarrollo de "comodidades urbanas" (cableados, wifi, etc.) puede habilitar pero también truncar diversas oportunidades; movilizaciones populares y junta de firmas en defensa del bosque nativo o la no intervención de los médanos vivos; discusiones en los concejos deliberantes locales sobre proyectos que ponen en riesgo el entorno natural de estos escenarios; recorridos con asociaciones ambientalistas realizando rescates de diversas especies animales y vegetales en peligro de extinción; entre otras. Sin la intención de profundizar en un tema tan complejo, incluimos el argumento de un entrevistado metropolitano para demarcar las representaciones que sustentan este tipo de prácticas que se multiplican es los espacios bajo análisis:

Como no tenía la naturaleza ahí al alcance de mi mano, como no la veía, no entendía que había que cuidarla ni que la estábamos destruyendo. Cuando me mudé acá entendí todo y empecé a participar de las asociaciones proteccionistas. Esta playa la tenemos que cuidar: hay que juntar la basura, limitar las construcciones, explicarles a los turistas que no pueden hacer lo que quieren porque este es un recurso muy importante. (MVG, 48 años)

Finalmente, en un juego de oposiciones, muchas de las personas que se desplazan señalan que la preponderancia de lo "natural" frente a lo "construido" habilita un escenario propicio para el desarrollo de un proyecto familiar que involucre la crianza de niños. Los testimonios reflejan la vinculación de 
la naturaleza con una infancia plena: "Vivía encerrada en el departamento, no salía a jugar con los amigos, no sabía andar en bicicleta. (...) Acá tiene una vida más feliz: en la calle, en las plazas, en el mar, con el bosque" (MVG, 37 años). De modo que los niños y las niñas tienen la posibilidad de desplegar diversas actividades en un entorno donde el contacto con el tejido vivo del que son parte es continuo. Hemos constatado que algunas de las actividades recreativas habituales de las familias son el senderismo de montaña, el reconocimiento de la flora y la fauna autóctona o los paseos al interior del bosque o a orillas del atlántico. Las propuestas educativas alternativas, como las que promueve la pedagogía Waldorf, también se constituyen en una pieza angular de la elección del cambio residencial ya que en estos escenarios suelen ser más frecuentes y accesibles que en otros contextos.

El cambio del estilo de vida es otra de las motivaciones para quienes deciden abandonar la gran ciudad. Este cambio involucra a la naturaleza, a las prácticas saludables, el autocuidado y la autocorrección, pero también versa sobre la necesidad de "volver hacia el pasado". Ese pasado se postula como un estado deseado frente a, como sostuvo un geselino, un "presente complicado". Ante el avance de prácticas consumistas, la competencia, la vinculación con la tecnología o el "despilfarro", estos espacios se presentan como libres de esos "males": "Acá estamos más lejos de todo eso, de esa intoxicación capitalista y consumista que te come" (MVG, 64 años). "Lo que más me gusta es la autenticidad, se sigue viviendo como hace cincuenta años. Todos tienen su huerta, la gente sigue transportándose a caballo. Esas cosas de pueblo que preservan su estado natural" (MLC, 54 años).
Hemos visto que el contacto con la naturaleza posibilitaría la recuperación de una experiencia ancestral y una vida saludable que fue mitigada por el avance de la creciente urbanización. Pero también el estilo de vida que puede practicarse en estas localidades parece erigirse como una recuperación de otros elementos desmantelados por el despliegue del "sistema capitalista y consumista": la sencillez, el ascetismo y la austeridad. "Me doy cuenta cuando estoy acá que al llegar a Buenos Aires los mensajes son icomprá, comprá! Si no tenés cosas no perteneces, todo te lleva a consumir" (MLC, 46 años).

El ritmo del habitar es otro de los motivos anudados al movimiento. Henri Lefebvre (2004) sostuvo que el ritmo expresa la interrelación entre el tiempo y el espacio. Cada lugar posee uno o varios ritmos que surgen de la yuxtaposición de las actividades cotidianas de las personas, la morfología del espacio y las estructuras sociales, económicas, políticas y culturales. Los ritmos pueden ser más o menos rápidos, cíclicos, ondulantes o constantes.

Si bien los especialistas señalan que el ritmo es una categoría "escurridiza" (Iparraguirre, 2011), difícil de aprehender mediante las técnicas habituales, lo cierto es que, al indagar sobre el universo de las motivaciones, los sujetos interpelados construyen argumentos en los que la temporalidad del espacio público y privado adquiere relevancia. Al respecto, los entrevistados coinciden en señalar que el ritmo de las nuevas localidades es más tranquilo y lento que aquel que han experimentado en las aglomeraciones de mayor tamaño: "Quería vivir más tranquila"; "Vivir a otro ritmo, sin la locura porteña"; 
"La ciudad me agotó, cumplió su ciclo"; "Allá vivía al palo [rápido], me enfermé, no podía seguir así". Estos testimonios se apoyan en algunos gestos cotidianos y prácticas vecinales que hemos registrado durante caminatas y recorridos comentados por los territorios. Así, sacar la silla a la vereda cuando baja el sol, "tomar fresco" y fomentar conversaciones con algún caminante u otros próximos, donde no solo surgen temas comunes sino también "chismes", es una particularidad arraigada al paisaje social. Al igual que "salir a la vereda", "dormir la siesta" o "caminar lento", para apreciar el entorno y observar a las personas que transitan por el espacio público, son comportamientos típicos que se enmarcan dentro de los rituales pueblerinos.

El ritmo más pausado, a su vez, tendría un impacto positivo en los modos de habitar. Quienes se trasladaron explican que "La tranquilidad, el tiempo que las personas tienen para escucharte (...), es otro clima en todo sentido, no sólo el clima de la naturaleza, el sol, la lluvia, es 'el clima de la gente'. Acá no te despachan, acá te atienden" (MLC, 54 años). Sin embargo, este estado, en torno al tiempo en que las actividades y la sociabilidad se despliegan, no parece ser igual de deseado para toda la población. Un estudio realizado con la juventud geselina (de Abrantes y Felice, 2015) mostró, por ejemplo, que este segmento de la población tiende a demarcar el aburrimiento, el letargo y la agonía de los tiempos locales: "Acá no pasa nada, es muy difícil ser joven en esta ciudad".

Otro de los elementos experienciales refiere a la escala o tamaño de estas localidades. Por un lado, esta característica, "la comunidad chica", menos densamente poblada, se configura como uno de los principales patrimonios para quienes se afincaron en estas localidades hace varias décadas; es decir, para los lugareños: "Acá nos conocemos todos con todos y también nos ayudamos en todo lo que podemos. La comunidad chica y la solidaridad son los patrimonios más importantes que tenemos y hay que cuidarlos" (LVG, 65 años).

Las cualidades detalladas aparecen, también, en las representaciones de quienes se encuentran organizando el movimiento como un estado deseado que salen a buscar. Así lo explica otra habitante metropolitana quien, luego de vacacionar múltiples veces en Villa Gesell, decidió, junto a su marido, emprender una nueva vida en esta localidad: "Volvimos a Buenos Aires, al caos, al destrato, a todo eso y dijimos basta: nos tenemos que mudar (...). La tranquilidad de la comunidad, eso de que todos se ayudan me da como una sensación de contención, de estar entre amigos (...) por eso tomamos esta decisión" (40 años).

La escala, en este sentido, habilitaría el despliegue de un lazo social más estrecho, redes solidarias más estables y contundentes, prácticas de intercambios y cadenas de favores. "Si se enferma alguien del pueblo sacamos el auto a cualquier hora y lo asistimos. Nos ayudamos entre vecinos (...). A veces si se carnea un animal nos prestamos una pata, o un costillar. Se conserva eso como antes (...)" (LLC, 31 años).

Estas redes de solidaridad y "de confianza" se desarrollan en un marco en donde el anonimato, estructura arquetípica de la vida urbana, no encuentra lugar entre las relaciones sociales. Como sostienen Greene y de Abrantes (2018, p. 228), en este tipo de escenario los vínculos se desarrollan "no entre completos extraños sino entre sujetos con 
mayor o menor grado de familiaridad, o que con pocos esfuerzos podrían dejar de serlo". Al respecto, un geselino argumenta: “Acá sigue funcionando el fiado. Vas a la farmacia y no tenés para pagar y no pasa nada. Volvés otro día y saldás la cuenta". Además insiste en comparar, a partir de su experiencia, el modo en que opera la sociabilidad en las grandes ciudades: "En Buenos Aires eso es imposible, ni en los barrios sigue funcionando el fiado. Allá sos uno más del montón" (LVG, 54 años).

En línea con estos hallazgos, las asociaciones vecinales representan espacios significativos para la comunidad. Los clubes, las cooperativas, los talleres y los espacios comunitarios congregan a una gran cantidad de habitantes que buscan, en sus palabras, "sentirse entre amigos y hacer cosas para el bien común", "pensar soluciones colectivamente", "ayudar a los que necesitan", "juntarse con el otro". Como señaló un entrevistado, esta característica sólo es posible gracias a la escala: “Acá todo se discute entre todos, el tamaño de este lugar también lo posibilita. En Buenos Aires no podés estar preguntándole a los millones que viven ahí si están de acuerdo con asfaltar una calle" (LVG, 64 años).

La vida apacible de la aldea otorga una imagen, frente al anonimato e inmediatez de la experiencia urbana, de calidez, solidaridad y encuentro fraternal pero también de seguridad. Así, el argumento de la seguridad aparece como otro de los estados a alcanzar. "Por eso nos fuimos. No fue fácil tomar la decisión, pero preferimos una vida en paz que una vida llena de miedos" (MVG, 50 años). En concordancia con este fragmento de entrevista, encontramos que las grandes ciudades aparecen como un espacio cargado de peligrosidad del cual huyen en busca de nuevas formas de vida en donde "la puerta abierta", "estar en la vereda", "no tener miedo", "caminar de noche", "no estar perseguido", entre otros textuales, parecen ser posibles.

Las oportunidades laborales vinculadas a la temporada turística son, por supuesto, otro de los factores que incide al moverse: "en verano hay trabajo hasta para el gato", explican los nativos. Revirtiendo el argumento que sostiene que las oportunidades suelen estar amarradas a las grandes ciudades, remiten, además, a cierta redistribución social que contrasta con la competencia "siniestra" de la gran ciudad: "Además de que hay trabajo en verano, el tema de que sea una ciudad chica ayuda mucho (...) hay más posibilidades siendo menos. Allá, en el Conurbano, conseguir trabajo es una odisea, es una competencia siniestra" (MVG, 26 años).

El conjunto de motivaciones que recuperamos evidencia cómo se despliegan los imaginarios sobre el antiguo lugar de origen, la gran ciudad, y el nuevo lugar de residencia, las medianas y pequeñas localidades. Estos imaginarios y prácticas se construyen a partir de contrastes entre blancos y negros, entre estados deseados y estados abandonados, entre paraísos e infiernos, entre lo vivido y lo posible. Es decir, los motivos no sólo permiten analizar de qué manera se figura, para quienes se mueven, el lugar de acogida, sino también el lugar del que huyen o se van. Este ejercicio nos permitió reconstruir una narrativa y un modo de habitar la metrópoli desde una perspectiva poco explorada: la de aquellos que alguna vez la han habitado, pero hoy deciden abandonarla. 
La gran ciudad se dibuja en un juego de tensión y alivio. Aunque el habitante se retire de la ciudad en la que ha crecido, aunque ya no quiera radicarse en ella, es una sombra que abraza sus dudas, sus certidumbres y sus formas de ser y estar en otros sitios. Se figura en los recuerdos, la mayoría de ellos poco felices, pero también en la añoranza. Esa añoranza, paradójicamente, comienza a hacerse lugar entre las representaciones cuando son interpelados por los motivos y la consecución de lo imaginado: ¿Aquello que salieron a buscar, finalmente, es encontrado? ¿Sus imaginarios sobre estas localidades se volvieron, de algún modo, realidad? Es aquí cuando muchos de los efectos de este tipo de movilidad residencial empiezan a emerger en las distintas voces de los protagonistas del movimiento.

\section{Los efectos de la movilidad como heurística socio-crono-espacial}

A continuación, presentamos los principales efectos que los flujos de personas (y todo lo que transportan) producen en su entorno socio-crono-espacial. Esta segunda dimensión heurística, que completa el "modelo para armar", se construye desde una tríada de transformaciones que tensan la trama móvil: las espaciales, las temporales y las relacionales. El supuesto-guía es que el tiempo y el espacio, así como los vínculos entre los habitantes, son continuamente redefinidos por la movilidad. ${ }^{15}$

La variable utilizada para desentrañar las transformaciones espaciales es la mutación morfológica, entendida como los cambios salientes en la apariencia externa (forma-estructura) e interna (de funcionamiento) del territorio. Es decir, examinamos cómo la movilidad residencial produce mutaciones en la configuración de las tramas territoriales que consecuentemente inciden en los modos de ocupación y de apropiación del espacio.

Para los habitantes atlánticos y serranos, desde hace aproximadamente dos o tres décadas, sus territorios comenzaron a cambiar o quizá conscientes de dichos cambios comenzaron a nombrarlos: "Hace 20 años estaba quietito todo". Estas transformaciones impulsadas por el crecimiento poblacional, en algunos casos leídas como sinónimo de "progreso" y en otras en términos de "desmejora", son evaluadas desde la referencia temporal "antes/ahora".

Los entrevistados suelen destacar, en primer lugar, los cambios que observan en la materialidad del paisaje indicando el avance del frente urbano y el trastocamiento de la "esencia paisajística del lugar": "Esto antes era un paraíso y mirá ahora: cemento por todos lados" (LVG, 70 años), "Si vos asfaltas le quitas la esencia al lugar. El estilo de vida, el paisaje se alteraría" (MLC, 56 años).

Estas marcas de la transformación material también se detectan en la sucesión temporal de mapas oficiales a los que hemos accedido a través del trabajo de archivo en dependencias locales. El caso de Villa Gesell muestra que la ondulación de la trama urbana característica de la localidad, calles que se pliegan a la fisionomía de los médanos, comenzó a dialogar hace varias décadas con la forma de la cuadrícula: calles paralelas, asfaltadas y con una disposición de viviendas mucho más contiguas (imagen en Figura 1). Algunas de las imágenes encontradas en el 
Archivo Municipal muestran, además, un proceso de multiplicación de edificios en altura que va ganando terreno a los chalets de techos a dos aguas y desplegando otra disposición y ocupación del territorio.

El asfalto, los semáforos, la cuadrícula, el cemento, la densidad, la cercanía entre viviendas, son algunas de las nuevas formas que empiezan a irrumpir en el espacio y a convivir con formas anteriores. "Todo esto empezó hace poco, con el crecimiento y las migraciones que Ilegan desde Buenos Aires" (LVG, 70 años). Asimismo, estos cambios producen transformaciones en las dinámicas sociales: "No se trata sólo de la belleza del paisaje sino de cómo nos relacionamos. Si vos caminas por los médanos en zigzag tardás 5 minutos por cuadra, si caminas en el asfalto recto tardas 1 minuto (...). Esos minutos cambian todo" (LVG, 70 años).

El crecimiento de las localidades también se ve acompañado de un proceso de estratificación social que encuentra su expresión en el espacio (Noel y de Abrantes, 2014). Ante esto, hemos encontrado que la elitización de la naturaleza funciona como una máscara de estos procesos: "Esta zona dicen que es más linda y exquisita porque trajeron árboles de Europa", "Si te fijás todas las casas lindas están en el bosque y cerca del mar", "Hay una gran división que se expresa en la estética de las casas y en la cercanía a la naturaleza". En ambos casos de estudio corroboramos que las fronteras sociales y materiales, como efecto de la movilización, se trazan sobre el espacio a partir de la localización de este recurso.

En Villa Gesell, una ciudad que se desarrolló en paralelo a la línea costera, pudimos constatar, a partir de recorridos comentados que realizamos junto a los habitantes, que las zonas de cercanía a la playa y al bosque condensan a los grupos más establecidos y son aquellas sobre las que se vuelcan las políticas públicas destinadas a embellecer, regular y ordenar el espacio. En Las Calles, por su parte, la posibilidad de estar cerca de la sierra, tener una casa con vistas y habitar un segmento del espacio alejado y lo menos densamente poblado, se convierte en uno de los aspectos más visibles del proceso de segregación.

Algunas apelaciones a la naturaleza, incluso, pueden volverse argumentos para el ejercicio de una "violencia civilizada" (Carman, 2011) sobre aquellos considerados "otros", "rústicos", "salvajes", "paisanos" o "pobres". La siguiente reflexión de un recién llegado sobre el proceso de desmalezamiento que llevan a cabo los lugareños, retrata este ejercicio: "El peón es obligado a matar las especies de su propio hábitat. ¿Cómo te vas a valorar si tuviste que liquidar todo tu hábitat con el cual tenías una relación anímica?" (MLC, 64 años).

Sin embargo, el crecimiento residencial no es el único proceso que impulsa mutaciones morfológicas. El turismo es otro factor capaz de desplegar diversas disputas entre ideas de desarrollo y conservadurismo. Aquí no profundizamos en esa movilidad estacional, pero sí destacamos que el avance de la frontera urbana, a partir de la conformación tanto de urbanizaciones residenciales como turísticas, compite por el suelo y el agua, desplazando, en algunos casos, a quienes moran y trabajan en dichos escenarios.

La expansión de la metrópoli en pequeñas y medianas escalas, por lo general, se desarrolla con escasa planificación previa y nula evaluación del impacto socio-ambiental que provoca. Los proyectos impulsados 
por los intereses del mercado inmobiliario, aprovechan, por un lado, la subvaloración de la actividad rural y el consecuente menor valor del suelo; y, por otro, la rentabilidad turística. Al analizar los despliegues burocráticos locales e interpelar a un conjunto de funcionarios, hemos detectado una llamativa ausencia de normativas que protejan y conserven las particularidades originales de los paisajes serranos y atlánticos. Es por ello que también nos ocupa aquel acaecer donde las formas de resistencia colectivas, en las que viene cobrando gran relevancia el Plan de Ordenamiento Territorial, ${ }^{16}$ dan cuenta del control sobre la producción y reproducción, a fin de cuentas, de los modos de habitar.

Frente a una territorialidad desbordada por el proceso de urbanización y por los paisajes de privilegio, algunos sectores sostienen la defensa de otro espacio asociado a sus experiencias, a sus sentidos de pertenencia y de identidad territorial, que no solo es para los propios habitantes, sino también para los potenciales turistas que buscan consumir ese espacio natural: "Por suerte pusieron una reglamentación para la parte edilicia porque lo lindo del pueblo es su tranquilidad... si vos llenas de cabañas se pierde el encanto" (MLC, 54 años). "Acá hay un plan de zonificación que debe ser cumplido (...) no podemos permitir que los negociados inmobiliarios vayan contra esa norma" (LVG, 32 años).

Por su parte, las transformaciones temporales de la movilidad emergen en el entrecruzamiento de temporalidades disímiles (metropolitanas y lugareñas) y son aquellas que configuran una experiencia "cronoliminal". Aquí queda tensionado el "tiempo del reloj" con el "tiempo glacial", es decir, el tiempo productivo y cronológico, con una percepción del tiempo más consciente del yo cosmológico que propone un ritmo vital de acción pausado, sin presiones y vinculado al contacto con la naturaleza (Castells, 2003).

La experiencia crono-liminal, como una fase de apertura, confluencia, choque y ambigüedad, simboliza la transición entre dos estados diferenciados. Desde este registro nos preguntamos: ¿Qué sucede en la concepción del tiempo de un grupo de personas que se traslada de su lugar de origen, vertiginoso y fugaz, a un territorio nuevo, tranquilo y bucólico? ¿Cómo se modifica la cotidianeidad de la sociedad receptora, inscripta en ciertos valores y costumbres, a partir de la llegada de otros ritmos? En ambos casos, ¿Cómo se vive la experiencia de un tiempo marcado por una epifanía?

Encontramos que quienes se movilizan, y llegan para quedarse, experimentan el pasaje de una secuencia temporal a otra y una suerte de "desfasaje". Esta disquisición queda reflejada en el testimonio de un metropolitano de Las Calles:

\footnotetext{
Vengo de trabajar 12 horas diarias en Buenos Aires. (...) Tenía dinero, una familia tipo... eso que llaman ser feliz. Tuve una crisis existencial y tomé la decisión de irme, renuncié a todo. La gente de acá tiene una tranquilidad envidiable, uno no nace con esa paz interna. (38 años)
}

Para estos sujetos, incluso, el tiempo parece habitarse como una experiencia escindida y antitética, cristalizada en el "invento de una rutina": "La vida en las sierras es tranquila, para no enloquecer me armé una rutina y durante la semana me tengo que despertar a las nueve de la mañana, ni sé 
bien para qué, pero me tengo que levantar" (MLC, 34 años). "Cuando llegué (...) no sabía qué hacer con el tiempo, era como que me sobraban horas. Estuve bastante confundida hasta que me fui acomodando a la rutina de este lugar" (MVG, 40 años).

El cambio de ritmo que conlleva el pasaje de una escala mayor, "vertiginosa", a otra menor, "de quietud", supone una ruptura biográfica casi perturbadora. El tiempo oscila entre un pasado y un presente. Se trata de una sucesión en la que los citadinos "metropolitanos" deberán dejar de ser lo que eran para ser lo que son ahora, generando un impacto en las probabilidades de los destinos de vida futura.

El deseo vehemente del residente metropolitano por adquirir un estado natural de "tranquilidad" (capital del que disponen los lugareños de manera innata) choca con una temporalidad ya adquirida cuando, por ejemplo, según un poblador de Las Calles, lo importante es "cumplir horario" con las sierras: "Llegas con un ritmo acelerado y hay que adaptarse, la gente acá maneja otras velocidades. En el valle no ando apurado, pero siento que tengo que cumplir horario con el paisaje" (56 años).

En un sentido similar, un habitante de la localidad balnearia relata algunas de las desconexiones temporales que percibió al llegar al nuevo escenario cuando trataba de abastecerse de ciertos productos: “¿Qué pasa con los negocios de esta ciudad? No entiendo cuándo abren y cuándo cierran. Es imposible manejarse con horarios tan estrictos, acá hay otros tiempos" (LVG, 58 años). Como contrapartida de estas experiencias, "los que están" tienden a delimitar las dificultades para adaptarse de "los que llegan":
No quiero hablar de la viveza que trae el de allá. A mí me ha tocado estar haciendo cola para entrar a la estación de servicio a cargar [nafta] y viene uno y se manda. Entonces, vos decís "éste no es de acá". Esa cosa, del que viene de afuera, que no se amolda, que le cuesta. Están acostumbrados a otro ritmo y por eso aparecen nuevos problemas con esos hábitos urbanos. (LVG, 48 años)

Los receptores del flujo poblacional también organizan las transformaciones entre un "antes" y un "ahora" que impone cambios en sus trayectorias, formas de sociabilidad y trabajo. Dichas referencias sintagmáticas manifiestan el disloque de la propia temporalidad: "Antes había poquitas casas", "ahora hay muchas casas"; "antes había gente buena", "ahora la gente ni te saluda"; "antes era más tranquilo", "ahora es todo un desorden"; "antes nos conocíamos entre todos", "ahora desconfiamos de nuestros vecinos"; "antes se plantaba tabaco", "ahora viven del turismo"; "antes cuidabamos a la naturaleza", "ahora la explotamos"; "antes la gente se tenía que ir a otro lado a trabajar", "ahora viene gente de afuera que quiere vivir acá".

Los testimonios y las prácticas analizadas indican que en el cruce de temporalidades se constituye un tiempo nuevo en donde los unos y los otros se ven obligados a reconfigurar sus propios marcos de sentido, negociar y adaptarse a los ritmos de la trama emergente. Algo parecido ocurre en un plano más macro, donde es destacable la existencia de otra superposición de temporalidades que responde a las características paisajísticas y productivas de estos lugares. En estas localidades más pequeñas las lógicas estacionales, las condiciones meteorológicas y 
el factor climático admiten un rol central en la organización de las actividades y en las formas del transcurrir.

El tiempo meteorológico, por ejemplo, impone restricciones y habilita cursos de acción. En el invierno, cuando las temperaturas descienden, los modos de habitar los territorios serranos y atlánticos se transforman radicalmente: "En invierno es muy tranquilo, hace mucho frío y recién podés asomar la cabeza después de las 10 de la mañana" (LLC, 31 años). "En verano esta ciudad es despampanante: tenés playa, sol, la avenida llena de negocios y restaurantes (...). En invierno cambia todo, hace muchísimo frío, los comercios cierran y los turistas se van. Es otra dinámica, se convierte en un pueblo fantasma" (LVG, 62 años). Esta dualidad que se figura como difícil para un lugareño, puede resultar hasta imposible para un recién llegado: "Pasar el invierno acá es muy difícil. No tiene ni punto de comparación con Buenos Aires. Allá si hace frío te ponés una campera y listo. Acá se te complica un poco la vida" (MVG, 42 años).

El invierno y el verano, ${ }^{17}$ además, marcan los ritmos y ciclos productivos. Al tratarse de puntos de atracción turística estival, que explotan sus cualidades paisajísticas al calor del sol, la actividad económica, la vida cotidiana y también la espacialidad se organiza estacionalmente: ${ }^{18}$ "En verano recibimos un millón de turistas y en invierno somos un pueblo de 40 mil habitantes; en verano estamos enloquecidos y en invierno no pasa nada. (...) Pasamos del pleno empleo al desempleo, así de la noche a la mañana El cambio es muy fuerte" (LVG, 32 años). "EI ritmo de vida del pueblo está determinado por las estaciones del año: en verano tenemos mucha corrida porque hay que trabajar para juntar platita para el invierno" (LLC, 60 años).

En el tejido temporal de las localidades se articulan entre sí el tiempo pausado del nativo y el acelerado del recién Ilegado. El tiempo del verano y el del invierno; el auge del trabajo y la inactividad; el tiempo del frío y el del calor. El tiempo mítico, el de la memoria y la reconstrucción histórica de un pasado sentido como mejor, y el de la esperanza, el del futuro.

Con transformaciones relacionales nos referimos al impacto de estos movimientos en las formas comunicativas, en las tramas culturales y en los espacios de interacción de las localidades. Para desentrañar este efecto perseguimos procesos de "etiquetamiento cruzado" como el resultado del arribo de subjetividades de la gran ciudad ("gringos", "hippies", "inmigrantes", "del conurbano", "porteños") a las localidades de menor escala. Nos preguntamos: ¿Qué trae consigo esa referencia a otros? ¿Qué se pone en juego en el contacto? ¿A partir de qué criterio se establece la autoctonía y la forestería?

La operación reflexiva que esgrimimos surge de la propia lectura que los habitantes realizan de ellos mismos en su encuentro con los otros. Hemos advertido que una de sus mayores preocupaciones es la mirada del "otro" y la falta de espacios de encuentro genuino entre "viejos y nuevos pobladores". Dicha inquietud nos advierte acerca de una primera gran tensión, aquella que da cuenta de procesos de construcción de otredad entre lugareños/forasteros; pueblerinos/ citadinos; establecidos/outsiders; nativos/ extranjeros; pioneros/recién llegados, viejos/ nuevos habitantes. Las movilidades impactan en la sociabilidad local articulando diferentes trayectorias biográficas, laborales, formativas y 
generacionales en las que se ponen en juego saberes y prácticas diferentes.

Ante esta situación, los antiguos habitantes referencian la llegada de "gente de afuera" como un problema: "No quiero que venga nadie más (...). Ahora no podemos tener animales porque a los vecinos de la ciudad les molesta (...) ¿Cómo pasó esto si nosotros estamos hace más años acá? Te sacan libertad. (LLC, 45 años). "Vienen, vienen y se quedan porque piensan que con la temporada alcanza, pero no. (...) esta ciudad no da para más. No puede seguir recibiendo gente con costumbres y tradiciones tan distintas (LVG, 30 años).

En esta sintonía, aquellos que Ilegan para quedarse aducen las dificultades que encuentran al arribar: "Al principio son bastante cerrados 'los paisa', tienen desconfianza porque ya tuvieron experiencias en las que algún pícaro los quiso aventajar y meten a 'los de afuera' en la misma bolsa" (MLC, 56 años). "Los primeros años son difíciles. La gente no te acepta tan rápido. Sos el que viene de otro lugar" (MVG, 42 años).

Los testimonios exponen cómo operan las fronteras sociales y el modo en que los protagonistas de este fenómeno procesan las distancias. Al decir de Pierre Bourdieu (1990), las categorías identitarias utilizadas por los actores siempre encubren vínculos de dominación y explotación. Las etiquetas "pionero", "del conurbano", "gringo", "hippie", "paisa", se inventan a partir de una caja de herramientas sedimentada en un territorio específico. Son tipificaciones situadas y utilizadas para realizar una clasificación de las subjetividades. Es decir, una taxonomía que supone toda una sensibilidad en relación al otro; una taxonomía de lo propio, de facción, de pertenencia, que permite clasificar a las personas según diversos atributos.

En el caso serrano, un recién llegado, argumenta su posición de privilegio frente a los antiguos pobladores de la localidad: "Nosotros tenemos que venir a decirles que las circunstancias han cambiado, que la alimentación orgánica es cada vez más importante... Siento que tengo una misión, con perdón de la palabra. Siento que debo hacerles abrir los ojos" (MLC, 64 años). Los lugareños, desde su lugar, apelan a la legitimidad que le otorga haber forjado ese pueblo: "Nosotros nos damos cuenta, no somos tan 'paisanos', esto recién empieza (...). Queremos proteger nuestra cultura" (LLC, 38 años).

En las localidades estudiadas confluyen grupos que despliegan procesos de alteridad (Hall, 2003; Briones, 2005; Grimson, 2011). Por ello, cuando nos referimos a lo "local", imaginamos un lugar poroso donde un conjunto de círculos desarrollan una sociabilidad del "entre nos" (Svampa, 2008). El círculo es la forma típica de sociabilidad en estos escenarios: el modo de asociación en el que se desarrollan las pautas que diferencian a unos y otros. Estas pautas distinguen la sociabilidad paisana o pionera, definida por el parentesco y la reciprocidad mutua, de la de los residentes metropolitanos, más proclives a una "sociabilidad de las afinidades electivas" (Svampa, 2008).

La imagen motora del círculo permite establecer relaciones entre las formas comunicativas y los espacios de interacción. En este testimonio de un residente de Las Calles, oriundo de la gran ciudad, se percibe con claridad el encuentro y desencuentro entre grupos: "El problema de la zona es juntar esas 
dos culturas. Hoy en día 'los de afuera' son los de Buenos Aires, son los 'hippies', 'los gringos', esos son" (59 años).

En Las Calles, observamos que la presencia de metropolitanos ("gringos" y "hippies") es casi nula en espacios públicos y sitios típicos de encuentro de la comunidad local: por ejemplo, en las fiestas patronales y festividades tradicionales. Además, las estrategias diferenciadoras de este grupo se vislumbran en actividades sociales y recreativas, así como en la elección de una determinada actividad espiritual o deportiva: el yoga femenino y el golf masculino.

Por su parte, quienes se movilizaron en estas últimas décadas hacia Villa Gesell tienden a localizarse en dos zonas bien diferenciadas de la ciudad: una que se despliega hacia atrás, lejos del frente costero (sectores populares con menos recursos "los del conurbano") y otra zona constituida por las localidades del sur (sectores medios más establecidos, "hippies"). Ambos sectores, que arribaron en un mismo período, suelen mantener clausurados sus círculos de sociabilidad sobre sí mismos: "Los de acá no nos juntamos con los de allá. Venimos de distintos lados, bah, en realidad tenemos distintos intereses" (MVG, 42 años). Más aún, existe un tercer círculo: "los pioneros", esas familias que forjaron y vieron nacer a la villa balnearia que mantienen sus tradiciones en los clubes de barrio, que organizan las festividades locales y se autodenominan como los verdaderos propietarios de la villa balnearia.

Ahora bien, no es la proximidad lo que reconforta la relación entre círculos, sino el conflicto y la distancia. El "modelo de murmuración" (Sennett, 2002), en este punto, se manifiesta como una de las expresiones de la convivencia. Vale recordar que "la chismografía constituye un intercambio irrestricto de información acerca de otras gentes; sus pecados, asuntos amorosos o pretensiones (...) donde estas intimidades constituyen el conocimiento común" (Sennett, 2002 , p. 146). Los habitantes geselinos nos explican sobre la preeminencia de este mecanismo como regulador de la vida social: "En una ciudad como ésta los chismes regulan mucho: los accesos y restricciones", "Acá todo se maneja por rumores: 'que éste es así,, 'que éste está con tal', 'que éste saca guita de allá' (...) así todo".

Al reconstruir las transformaciones relacionales, encontramos, por un lado, un proceso de "etiquetamiento cruzado"; y, por otro, un "modelo de sociabilidad en círculos" que tienden a cerrarse sobre sí mismos. Estas dinámicas se montan sobre relaciones de desigualdad y poder que expresan una puja por la legitimidad del habitar, por la auténtica posesión del territorio, por la defensa de las tradiciones y por la posibilidad o no de formar parte de la comunidad.

\section{Reflexiones finales}

Este trabajo profundizó el análisis de un tipo de movimiento poblacional que implica no sólo un cambio de residencia sino también uno de escala: aquel que se originan en las grandes ciudades para afincarse en localidades de menor tamaño. Estos movimientos, poco explorados por las agendas locales, se constituyen en un factor clave para entender las dinámicas de asentamiento poblacional de la Argentina contemporánea, en particular, 
pero quizás también de otros escenarios con características similares.

Desde "la potencia" que encontramos en el paradigma de la movilidad, y con un corrimiento de los tradicionales estudios de las migraciones, delineamos un modelo teórico y metodológico (un registro móvil) para analizar algunas características modulares del fenómeno. Este modelo que llamamos "para armar", porque invita a la construcción continua, se levantó sobre un conjunto de datos cualitativos recogidos mediante un trabajo de campo prolongado en dos localidades argentinas con algunos rasgos similares y otros contrastantes.

El ejercicio etnográfico permitió delinear dos dimensiones para emprender el abordaje: las motivaciones que impulsan el movimiento y las transformaciones que generan en los territorios de acogida. Esas dimensiones fueron adquiriendo capacidades analíticas reveladoras al verse nutridas de un conjunto de elementos experienciales, de prácticas y representaciones situadas, capaces de caracterizar y problematizar al fenómeno del movimiento.

Por un lado, el abordaje del repertorio motivacional nos permitió encontrar narrativas contundentes sobre los espacios abandonados y los espacios deseados. Así, la naturaleza, los estilos de vida, la escala, el lazo social, la distribución de oportunidades, el anonimato y la solidaridad, la sensación de seguridad o el consumismo, se postularon como los principales tópicos de los argumentos de quienes se mueven. Por otro lado, el análisis de las transformaciones espaciales, temporales y relacionales, reconstruidas a través de las voces de "los que llegan" y "los que están", como así también desde el registro de sus prácticas, nos permitió observar la emergencia de un tipo de espacio, de tiempo y de vínculo que hace conjugar, en presente, algo que se intuye como opuesto. El trabajo de campo y los métodos móviles, en definitiva, develaron que más allá de las expresiones duales, las construcciones de alteridad y la tensiones sociales, las movilidades motorizan intersticios, pliegues y mixturas.

Así, el análisis de ambas dimensiones nos condujo hacia el encuentro de "zonas liminales" en donde se entretejen, produciendo una otra cosa, diversos elementos que parecen no haber sido concebidos para coexistir. En estos lugares convive el paisaje prístino con las intervenciones urbanas; el tiempo del verano y el tiempo del invierno; el tiempo pueblerino con el metropolitano; la idealización del pasado con la esperanza futura de los que llegan; el lazo social pequeño con el anonimato; los deseos de los que abandonan la gran ciudad con los temores de quienes reciben.

Paul B. Preciado (2019) sostiene que el universo entero está cortado en dos y solamente en dos. "En este sistema de conocimiento, todo tiene un derecho y un revés. Somos el humano o el animal. El hombre o la mujer. Lo vivo o lo muerto. Somos el colonizador o el colonizado. El organismo o la máquina" (2019, p. 23). Somos "lugareños" o "metropolitanos", "ellos" o "nosotros". "La norma nos ha dividido (...) Y forzado después a elegir una de nuestras partes. Lo que denominamos subjetividad no es sino la cicatriz que deja el corte en la multiplicidad de lo que habríamos podido ser" $(2019$, p. 23).

Uno de los elementos más sobresalientes de este tipo de movilidad residencial es, justamente, la apertura del interrogante por la identidad dual. El arribo de nuevas 
subjetividades, el encuentro con un otro y las tensiones por la autoctonía, esconden este tipo de pregunta: ¿Qué somos: un pueblo o una ciudad? ¿Somos el estado virgen de la naturaleza o la intervención del cemento y los cableados? ¿Somos lentos o acelerados? ¿Somos el pasado o el futuro? ¿Somos lugareños o metropolitanos?

Hemos visto que en las localidades estudiadas existe una inminente necesidad por identificarse y clasificarse unos con respecto a los otros, pero también de definir, conjuntamente, las nuevas formas de ser, estar y habitar el espacio compartido. En esa convivencia conflictiva de subjetividades, unos y otros, disputan la autoridad de la definición. Sin embargo, en ese disputar también se están transformando a sí mismos.
No se trata, entonces, de abandonar un espacio, un ritmo, una escala, para asumir necesariamente otra; tampoco de lo que se importa de otros escenarios, de lo que se resiste, se cede o se pierde. Se trata, por el contrario, de lo que emerge del encuentro, de lo que convive. No importa, así, si dejaron de ser metropolitanos para convertirse en lugareños, tampoco si el pueblo se volvió una metrópolis en miniatura o si los ritmos producen desfasajes biográficos y la naturaleza retrocede ante al avance del frente urbano. No es de un lado o del otro; son los "cruces", diría Preciado (2019), son los intersticios, preferimos alegar nosotras, aquello que nos permite comprender la trama compleja y conflictiva que motorizan las movilidades.

\section{[I] https://orcid.org/0000-0002-3066-3417}

Universidad Nacional de San Martín, Instituto de Altos Estudios Sociales, Centro de Estudios Socioterritoriales, de Identidades y de Ambiente. San Martín, Provincia de Buenos Aires, Argentina. deabranteslucia@gmail.com

\section{[II] https://orcid.org/0000-0002-5634-8175}

Consejo Nacional de Investigaciones Científicas y Técnicas, Centro de Investigaciones y Estudios sobre Cultura y Sociedad, Universidad Nacional de Córdoba. Córdoba, Argentina.

lucianatrimano@gmail.com

\section{Notas}

(1) Con excepción de los censos realizados cada diez años, en la Argentina no existe una política estadística que recoja datos sistemáticos sobre aglomeraciones de menor escala. Tampoco, con este relevamiento, se recuperan los movimientos poblacionales intra-provinciales. La Encuesta Permanente de Hogares (EPH) que releva sistemáticamente los principales indicadores sociales, no se realiza en este tipo de escenarios; está dirigida a ciudades que superan los 200.000 habitantes (de Abrantes, 2018). 
(2) La investigación en Villa Gesell comenzó el año 2014 y en Las Calles en el 2010; ambas continúan desarrollándose en la actualidad.

(3) El camino viejo no pasaba por la actual RP 14, principal arteria vial de movilidad y acceso a la región realizada en la década del treinta.

(4) Una de las localidades de San Alberto con mayor concurrencia turística. Se encuentra colindante a Las Calles accediendo por la RP 14.

(5) Asentamiento poblacional de hasta 2.000 habitantes (Ley Orgánica n. 8102/91 de Municipios de Córdoba).

(6) Las periodizaciones nativas de los distintos movimientos poblacionales que se afincaron en Villa Gesell y Las Calles fueron reconstruidas a partir de los datos relevados en las entrevistas, el análisis de fuentes documentales y la lectura de un conjunto de producciones locales de corte historiográfico. Tanto las fuentes documentales como las producciones locales son consideradas en este texto como parte del repertorio nativo y no como antecedentes analíticos de la problemática.

(7) Este paraje se ubica geográficamente "arriba" del casco céntrico de Las Calles donde habita la mayor parte de la población "lugareña".

(8) Según datos de los últimos censos nacionales (2001-2010), Las Calles presenta un aumento de población de más del $30 \%$.

(9) El Amba es la zona urbana común que conforman la Ciudad de Buenos Aires y el Gran Buenos Aires (40 municipios de la provincia de Buenos Aires que se organizan en tres cordones que rodean a la ciudad capital).

(10) El AMC es el área centro-norte establecida por 46 localidades alrededor de la ciudad de Córdoba. Incluye el aglomerado urbano denominado Gran Córdoba y localidades más lejanas que constituyen una red de influencia recíproca (Iplam-Ley n. 9841).

(11) Se conoce como Conurbano Bonaerense a los 24 partidos de la provincia de Buenos Aires que rodean en forma de cordones a la ciudad capital. Aunque esta categoría es utilizada desde hace décadas para identificar una realidad geográfica y social, lo cierto es que no posee un claro estatuto jurisdiccional, político ni administrativo (Segura, 2015).

(12) En estas localidades también existen flujos poblacionales hacia afuera. Aunque estos movimientos son menos populosos, mayoritariamente son los jóvenes quienes se mueven hacia otros espacios de mayor escala en busca de oportunidades de estudio y/o trabajo.

(13) Establecemos la diferencia entre "metropolitanos" y "lugareños" para demarcar los grupos sociales que conviven en las localidades y entre los que se despliegan las disputas analizadas. Metropolitanos son quienes, socializados en ámbitos urbanos y metropolitanos, se movilizan desde las grandes ciudades y arriban con las últimas olas poblacionales; lugareños, aquellos que nacieron en esos espacios o hace varias décadas que lo habitan. Para agilizar la lectura utilizamos las siglas MLC para referenciar "metropolitano/a de Las Calles" y MVG para metropolitano/a geselino/a. Asimismo, LLC corresponde a lugareño/a de Las Calles y LVG, lugareño/a de Villa Gesell.

(14) Pertenecer a un hábitat donde se prioriza lo simbiótico sobre lo semiótico (Massoni, 2016) en tanto los objetos naturales también son sujetos de derechos. 
(15) Un análisis extendido sobre las fantasías que impulsan la salida de la metrópoli y las fricciones que desata el encuentro con una realidad no contemplada puede encontrarse en (de Abrantes; Greene; Trimano, 2020).

(16) Es una norma, que desde un enfoque eco-sistémico y a partir de las necesidades de las poblaciones, plantea lineamientos y acciones para ordenar el territorio (Barchuk; Britos; De la Matta, 2009).

(17) El invierno comprende, desde el punto de vista nativo, el período entre abril y octubre, y el verano, los meses restantes, siendo el pico más alto en enero y febrero.

(18) La concentración del empleo durante la temporada estival configura otra arena de disputa entre lugareños y metropolitanos. Sumado a las tensiones espaciales que genera el turismo, aparecen representaciones encontradas en torno a quienes son los que "merecen" ocupar los puestos de trabajo disponibles. Esta dimensión, al igual que otras de corte político, serán presentadas en un próximo trabajo ya que el modelo analítico, como advertimos, invita a sumar elementos que complejizan el abordaje de los movimientos.

\section{Referencias}

ARANGO, J. (2000). Enfoques conceptuales y teóricos para explicar la migración. Revista Internacional de Ciencias Sociales. Madrid, v. 53, n. 3, pp. 282-296.

ARROYO, M. (2001). La contraurbanización: un debate metodológico y conceptual sobre la dinámica de las áreas metropolitanas. Scripta Nova. Barcelona, v. 97.

BARCHUK, A.; BRITOS, A.; DE LA MATTA, E. (2009). Diagnóstico de la cobertura de bosques nativos de la provincia de Córdoba. Sistema de Información Geográfico. Inédito. Grupo de Investigación de Ordenamiento Territorial Participativo. Universidad Nacional de Córdoba.

BENSON, M.; O'REILLY, K. (2009). Lifestyle migration: expectations, aspirations and experiences. Londres, Ashgate.

BOURDIEU, P. (1990). Sociología y Cultura. México, Grijalbo.

BRIONES, C. (2005). "Formaciones de alteridad: contextos globales, procesos nacionales y provinciales". En: BRIONES, C. (ed.) Cartografías Argentinas. Políticas indigenistas y formaciones provinciales de alteridad. Buenos Aires, Antropofagia.

CAMARERO RIOJA, L. (1993). Del éxodo rural y del éxodo urbano. Ocaso y renacimiento de los asentamientos rurales en España. Madrid, Estudios.

CARMAN, M. (2011). Las trampas de la naturaleza. Medio ambiente y segregación en Buenos Aires. Buenos Aires, FCE.

CASTELL, M. (2003). "El reverdecimiento del yo: el movimiento ecologista”. En: CASTELL, M. La era de la información. Economía, sociedad y cultura. El poder de la identidad. V. II. Buenos Aires, Siglo XXI. 
CHAMPION, A. (1989). Counterurbanization. The changin pace and nature of population deconcentration. Londres, Arnold.

CHEVALIER, M. (1981). Les phénomenes néoruraux. L'Espace Géographique. Paris, n. 1, pp. $33-49$.

COSACOV, N.; DI VIRGILIO, M. (2019). Movilidades espaciales de la población y dinámicas metropolitanas en ciudades latinoamericanas. Quid 16. Buenos Aires, n. 10, pp. 1-16.

CRESWELL, T. (2006). On the move. Mobility in the modern western world. New York, Routledge.

DE ABRANTES, L. (2018). Habitar entre polos. Una etnografía de las experiencias de transformación urbana en una ciudad media bonaerense. Tesis de maestría. FLACSO, Argentina.

DE ABRANTES, L.; FELICE, M. (2015). ¿Ciudad sin jóvenes o jóvenes sin ciudad? Reflexiones sobre el derecho a la ciudad en jóvenes que habitan en ciudades intermedias. Cuaderno Urbano. Resistencia, v. 19, n. 19, pp. 115-136.

DE ABRANTES, L.; TRIMANO, L. (2019). Movilidades residenciales en pequeñas y medianas aglomeraciones argentinas. Segunda Escola de Ciência Avançada em Mobilidades (SPMob2019). (Des)Igualdades em movimiento. Mobilidades e o urbano na América Latina - Universidade de São Paulo.

DE ABRANTES, L.; GREENE, R.; TRIMANO, L. (2020). Huir de la metrópolis y de la pandemia. Ciper/ Académico.

GERMANI, G. (1974). El surgimiento del peronismo y los migrantes internos. Desarrollo Económico, n. 55.

GREENE, R.; DE ABRANTES, L. (2018). “El modo de vida en ciudades no-metropolitanas: disolviendo el binarismo urbano/rural". En: GREENE, R. (ed.). Conocer la ciudad. Imaginarios, métodos, cartografías, sentidos. Santiago de Chile, Bifurcaciones.

GRIMSON, A. (2011). Los límites de la cultura. Crítica de las teorías de la identidad. Buenos Aires, Siglo XXI.

GURRAN, N. (2011). "Migración residencial y transformación social en las costas australianas". En: MAZÓN, T.; HUETE, R.; MANTECÓN, A. (eds.). Construir una nueva vida. Los espacios del turismo y la migración residencia. Santander, Milrazones.

HALFACREE, K. (2001). Constructing the object: taxonomic practices, 'counterurbanization' and positioning marginal rural settlement. International Journal Population Geography, v. 7, n. 6, pp. 395-411.

HALL, S. (2003). “Introducción: ¿quién necesita 'identidad’?”. En: HALL, S.; DU GAY, P. (comps.). Cuestiones de identidad cultural. Buenos Aires, Amorrortu.

IPARRAGUIRRE, G. (2011). Antropología del tiempo. El caso Mocoví. Buenos Aires, Sociedad Argentina de Antropología.

JIRÓN, P. (2012). Transformándome en la sombra. Bifurcaciones. Santiago de Chile, n. 10, pp. 1-14.

LATTES, A. (2007). "Esplendor y ocaso de las migraciones internas". En: TORRADO, S. (comp.). Una historia social del siglo XX. Tomo II. Buenos Aires, Edhesa. 
LEFEBVRE, H. (2004). Análisis del Ritmo. Ritmo-análisis: espacio, tiempo y vida cotidiana. Nueva York, Continuum.

MASSERONI, S. (2018). Los estudios sobre migraciones y la formación de investigadores en Argentina. @-migrinter. Poitiers, v. 17.

MASSONI, S. (2016). Avatares del comunicador complejo y fluido. Del perfil del comunicador social y otros devenires. Quito, Ciespal.

MEICHTRY, N. (2007). “Emergencia y mutaciones del sistema urbano”. En: TORRADO, S. (comp.). Una historia social del siglo XX. Tomo II. Buenos Aires, Edhesa.

MOSS, L. (2006). The amenity migrants. Seeking and sustaining mountains and their cultures. UK, Cabi.

NAKAYAMA, L.; MARIONI, S. (2007). Migración por opción: El fenómeno migratorio en destinos turísticos de montaña. Revista Brasileira de Pesquisa em Turismo. San Pablo, v. 1, n. 2, pp. 101-136.

NATES CRUZ, B.; VELÁSQUEZ LÓPEZ, P. (2019). Gentrificación rururbana. Estudios territoriales en la Florida (Manizales-Villamaría) y Cerritos (Pereira) Colombia. Territorios. Colombia, v. 41, pp. 143-170.

NOEL, G.; DE ABRANTES, L. (2014). La gran división. Crecimiento y diferenciación social en una ciudad balnearia de la costa atlántica bonaerense. Argumentos, n. 16, pp. 141-166

PERREN, J. (2011). Las migraciones internas en la Argentina moderna. Una mirada desde la Patagonia: Neuquén, 1960-1991. Buenos Aires, Prometeo.

PRADOS, M. (2011). Naturbanización. Ejemplos en áreas de montaña y periurbanas. Sociedad Catalana de Geografía. Barcelona, v. 71, n. 72, pp. 179-200.

PRECIADO, P. B. (2019). Un apartamento en Urano. Crónicas del cruce. Barcelona, Anagrama.

SEGURA, R. (2015). “La imaginación geográfica sobre el conurbano. Prensa, imágenes y territorio”. En: KESSLER, G. (ed.). Historia de la Provincia de Buenos Aires. Tomo 6: El Gran Buenos Aires. Buenos Aires, Unipe y Edhasa.

SENNETT, R. (2002). El declive del hombre público. Barcelona, Península.

SHELLER, M.; URRY, J. (2018). Movilizando el nuevo paradigma de las movilidades. Quid 16. Buenos Aires, n. 10, pp. 333-355.

SVAMPA, M. (2008). Los que ganaron: la vida en los countries y barrios privados. Buenos Aires, Biblos.

THOMPSON, E. P. (1995). “Introducción: Costumbre y cultura y Patricios y Plebeyos”. En: THOMPSON, E. P. Costumbres en común. Barcelona, Grijalbo.

TRIMANO, L. (2017). Paisas y gringos. Neorruralidad serrana, transformaciones relacionales e identidades emergentes. Chungara, v. 49, n. 3, pp. 461-471.

(2019). ¿Qué es la neorruralidad? Reflexiones sobre la construcción de un objeto multidimensional. Territorios, n. 41, pp. 119-142.

TRIMANO, L.; DE ABRANTES, L. (2017). Procesos de comunicación y nuevas movilidades en pequeñas y medianas aglomeraciones argentinas. Ponencia presentada en las IV JORNADAS INTERNACIONALES DE SOCIOLOGÍA DE LA AMS. UCM, Madrid. 
TRIMANO, L.; DE ABRANTES, L. (2018). De elegías y encanto. Pensar la gran ciudad desde afuera. Ponencia presentada en el III CONGRESO INTERNACIONAL DE VIVIENDA Y CIUDAD. FAUD, UNC, Argentina.

URRY, J. (2007). Mobilities. Cambridge, Polity.

ZUNINO SINGH, D.; GIUCCI, G.; JIRÓN, P. (eds.) (2018). Términos clave para los estudios de movilidad en América Latina. Buenos Aires, Biblos.

Texto recebido em $2 / \mathrm{mar} / 2020$

Texto aprovado em 4/ago/2020 
